\title{
A Study on the Determination of Korea Affecting Tropical Cyclone Center for Best Tracking
}

\author{
Yumi Cha, Jinyeon Kim, Kiryong Kang, Nam-Young Kang, and Won-Tae Yun \\ National Typhoon Center, Korea Meteorological Administration, Add 2 Seoseongro 810-gil, Seogwipo, Jeju 63614, Republic of Korea \\ Correspondence should be addressed to Yumi Cha; finedrop@korea.kr
}

Received 15 September 2015; Revised 14 December 2015; Accepted 27 January 2016

Academic Editor: Olivier P. Prat

Copyright ( $) 2016$ Yumi Cha et al. This is an open access article distributed under the Creative Commons Attribution License, which permits unrestricted use, distribution, and reproduction in any medium, provided the original work is properly cited.

\begin{abstract}
The establishment of an independent tropical cyclone (TC) position is suggested for the purpose of constructing TC best track data of the Korea Meteorological Administration. The best track process was designed with five basic stages: database, potential interval (PI), optimization, smoothing, and metadata. The PI was newly devised as a tool for expressing the uncertainty in the location of the center of the TC. This PI determined the minimum range at which the center of the TC can be adjusted and based on the analysis manual for each dataset used in the TC best tracking. Furthermore, the PI can be optimized by the differential application of the range depending on the reliability of the data. By smoothing all TC centers within the optimized PI, a best track can be produced more stably. Therefore, the analysis can be less subjective even when the determination of the TC center is difficult. For three typhoon cases that had affected Korea in 2013 (LEEPI, KONG-REY, and DANAS), best tracks were obtained based on the suggested analysis stages and verified. The results showed that the PI was relatively large in the early development and weakening stage of the TC or when the estimation of the TC center was difficult because of interactions with the land. And the best tracking was performed well with reasonable applicability.
\end{abstract}

\section{Introduction}

A tropical cyclone (TC) is a natural disaster that can lead to significant damage to property and life. TCs are responsible for the establishment of national disaster prevention measures and serve as an important research topic for understanding how global warming impacts weather conditions. Thus, high-accuracy TC data is necessary for securing policy and obtaining accurate research results.

Unprocessed real-time TC data has been provided to the public by the Korea Meteorological Administration (KMA). This data is provided along with the TC forecast in a timely manner to supply the latest information in a short timeframe for the safety of the public when the TC is active. This is especially appreciated when direct damage to the Korean Peninsula is expected. However, the available data is limited because the analysis is rapidly performed, which may induce error and uncertainty in the analysis due to insufficient examination. Hence, the unreliability of the data has forced experts to utilize the data from other agencies.
Postanalysis is performed following the storm to validate and determine the uncertainties of the real-time analyzed data. The renewed data is referred to as "best track." Major agencies such as the Regional Specialized Meteorological Centers (RSMCs) and the Tropical Cyclone Warning Centers (TCWCs) have already performed the International Best Track Archive for Climate Stewardship (IBTrACS) project for the purpose of climate management [1]. The largest number of agencies in the western North Pacific region, which include the Joint Typhoon Warning Center (JTWC), RSMCTokyo, Shanghai Typhoon Institute of China Meteorological Administration, and Hong Kong Observatory, has produced their own best tracks.

The production of a best track is challenging and requires high-level observation techniques and analytical skills. A TC spends most of its life on the sea, and it is usually formed in the deep tropical latitudes and travels a long distance to the midlatitudes. The diameter of the eye can range from several $\mathrm{km}$ to dozens of $\mathrm{km}$, and thus precise detection should be possible regardless of time and space. Nowadays, observation 
networks are rapidly developed, so that the weather in a small town on the opposite side of the Earth can be known. Direct weather observations over the ocean are difficult, but various remote observation techniques (e.g., satellite, aircraft, and radar) are filling this gap.

Nevertheless, in some cases, the best tracks of each agency exhibit considerable differences. Martin and Gray [2] found that the largest $10 \%$ of the position differences between JTWC and RSMC-Tokyo during 1988-1998 are greater than $107 \mathrm{~km}$. They also investigated TC position differences between aircraft and satellite (greater than $93 \mathrm{~km}$ in upper 10\%) and between multiple satellites (greater than $110 \mathrm{~km}$ in upper 10\%) and showed that differences can occur depending on the data used. Chang et al. [3] found that the mean position difference determined by different agencies is smaller than $35 \mathrm{~km}$. However, the maximum difference of each typhoon is $72-114 \mathrm{~km}$ on average, with the largest being $272.1 \mathrm{~km}$ for 11 typhoon cases during 2010-2012. These TC position ambiguities are due to the analysis method and data used by each agency and the subjective judgment of the analyst [4]. Furthermore, when the TC intensity is weaker, the differences increase $[3,5]$. Therefore, for the "best track," the purpose is to minimize the uncertainty of the initial analysis so that it can be close to a true value, rather than obtaining the true value.

In this study, a systematic method is proposed so that the uncertainty of the TC position can be expressed and reduced, and postanalysis can be reliably and reproducibly performed. For this purpose, the postanalysis of the typhoon cases that affected the Korean Peninsula in 2013 (LEEPI, KONG-REY, and DANAS) was performed as a pilot study for the design of best track production system, and the suggested best tracking method was verified by comparing with results.

In Section 2, the postanalysis data and the analysis manual for each data are introduced. In Section 3, the uncertainty of the TC position and a method for expressing it are suggested, and a basic process for postanalysis is organized. In Section 4, analysis examples for each actual data are presented based on the manual introduced in Section 2. In Section 5, the postanalysis method is verified by comparing the best tracks of the 2013 Typhoons LEEPI, KONG-REY, and DANAS with the best tracks from JTWC and RSMC. Lastly, in Section 6, the contents of this study are summarized, and a detailed flowchart for the determination of a best track is drawn.

\section{Data and Methodology}

2.1. Data. This study proposes a method for TC center positioning and experimentally produces six-hour interval best tracks for the three typhoon cases that affected Korea in 2013. The postanalysis period was initiated starting one day (24 hours) before naming as a tropical storm to when the storm had weakened to a tropical depression or extratropical transition. The times ranged from 00 UTC on 17 June to 00 UTC on 21 June for Typhoon LEEPI, 06 UTC on 25 August to $06 \mathrm{UTC}$ on 30 August for Typhoon KONG-REY, and 06 UTC on 3 October to 00 UTC on 9 October for Typhoon DANAS. Table 1 summarizes the data used for positioning the center of the TC. To verify the estimated best tracks and compare with other agencies, the KMA's real-time TC analysis data and the best tracks provided from RSMC-Tokyo and JTWC during the period of the activity of the same three typhoons were used.

2.2. Analysis Method for Each Dataset. It is important to understand the characteristics of the data and to analyze them accordingly, because the accuracy of the analysis is influenced by the quality of the data and the analytical skill. Analysts can acquire the surface wind and pressure around the estimated location of the TC center using in situ and remote sensors. The in situ observation network including ships and buoys makes surface measurements at specific locations and times. However, remote observations, such as satellite and radar images, are based on almost continuous snapshots taken from the air. To analyze a TC, which spends most of its life on the ocean, remote observations are used. However, this could induce a significant difference between the derived position of the TC center and its actual position on the ground. Therefore, analysis methods for each data need to be known before the postanalysis.

The collected data introduced in Table 1 can be broadly classified into fixed data (latitude and longitude of the position of the TC center determined by each agency or model), visible/infrared images, microwave images (including ocean surface wind products derived from scatterometers), radar images, and surface observation data. TC centers related to different data, except fixed data, can be analyzed by using an analysis manual for existing satellite images, radar images, synoptic data, and so forth. Table 2 summarizes the manual of each data that was used in the TC position analysis. For the sea surface wind data, the position of wind convergence (center of the rotation) was determined as the potential location of the TC eye. However, when using this data, the accuracy of the estimation is low when the intensity is weak, and thus it should reflect the location of the TC center through comparison with other satellite images. For the surface observation data on land, the spatial distribution and the lowest/highest values of sea level pressure, and the maximum wind speed are expressed, and thus these can be used.

\section{Postanalysis Method}

3.1. Uncertainty of the TC Analysis. To enhance the quality of the best track, utilizing most of the available data is necessary. However, as the spread in the different datasets increases, there could be more uncertainty in determining the location of the TC center. Therefore, even if we use as much data as possible, we cannot calculate the best track that is identical to the actual typhoon location and uncertainty in analysis is inevitable. At the RSMC, Dvorak analysis using satellite images is reviewed in consideration of all of the stages of TC, from genesis to dissipation, and the estimated TC center is supplemented using additional data $[6,7]$. The final best track is determined by examining the consistency using a weather map [8], and the uncertainty of the analysis is not expressed.

At the JTWC or National Hurricane Center (NHC), which produces a best track using the Automated Tropical Cyclone Forecasting (ATCF (Automated Tropical Cyclone 
TABLE 1: List of data used for TC center positioning in this study.

\begin{tabular}{|c|c|c|c|c|}
\hline Classification & Agency/satellite & Sensor & Used data or images in this study & Time interval \\
\hline \multirow{2}{*}{$\begin{array}{l}\text { Stationary } \\
\text { satellite images }\end{array}$} & \multirow{2}{*}{ COMS } & & Infrared (IR) and shortwave infrared (SWIR) & \multirow{2}{*}{$15 \mathrm{~min}$} \\
\hline & & & Visible & \\
\hline \multirow{6}{*}{$\begin{array}{l}\text { Microwave } \\
\text { (MW) images }\end{array}$} & DMSP F-12 F-15 & SSM/I & $37 \mathrm{GHz}, 85 \mathrm{GHz}$, color & \multirow{6}{*}{ Irregular } \\
\hline & DMSP F-16 F-17 & SSMIS & $37 \mathrm{GHz}, 91 \mathrm{GHz}$, color, wind & \\
\hline & TRMM & TMI & $37 \mathrm{GHz}, 85 \mathrm{GHz}$, color, wind & \\
\hline & GCOMW-1 & AMSR-2 & $37 \mathrm{GHz}, 89 \mathrm{GHz}$, color & \\
\hline & NOAA-18, NOAA-19, and METOP-A & AMSU-B & $89 \mathrm{GHz}$, color & \\
\hline & CORIOLIS & WINDSAT & $37 \mathrm{GHz}$, color & \\
\hline \multirow{3}{*}{ Scatterometer } & CORIOLIS & WINDSAT & & \multirow{3}{*}{ Irregular } \\
\hline & METOP-A, B & ASCAT & Ocean surface wind & \\
\hline & OCEANSAT-2 & OSCAT & & \\
\hline Radar images & KMA & & $\mathrm{VR}, \mathrm{CZ}$, and so forth & $10 \mathrm{~min}$ \\
\hline \multirow{10}{*}{ Fixed data } & KMA & & & \multirow{10}{*}{$30 \mathrm{~min} \sim 12 \mathrm{hr}$} \\
\hline & NMSC/KMA & & & \\
\hline & RSMC & & OPS, ADT, and DVTS & \\
\hline & SAREP & & & \\
\hline & JTWC & & & \\
\hline & CIMSS & & SATC and AMSU & \\
\hline & NSOF & & AMSU, CD, WV, IR, ASCAT, and QSCAT & \\
\hline & NESDIS & & DVTS & \\
\hline & CIRA & & AMSU & \\
\hline & Others & & Analyzed data using many models (ANALYS) & \\
\hline \multirow{2}{*}{ Synoptic data } & International & & Surface station, ship, buoy, and so forth from RBSN & $3 \mathrm{hr}$ \\
\hline & Domestic & & Surface station, AWS, buoy, and so forth & $5 \mathrm{~min}$ \\
\hline Weather charts & KMA & & Steering flow, streamline, surface chart, and so forth & $3 \sim 12 \mathrm{hr}$ \\
\hline
\end{tabular}

TABLE 2: References for tropical cyclones analysis using visible/ infrared, microwave and radar imagery, and synoptic surface data.

\begin{tabular}{|c|c|}
\hline Observations & $\begin{array}{l}\text { Manuals and references for TC center } \\
\text { positioning }\end{array}$ \\
\hline $\begin{array}{l}\text { Visible/Infrared } \\
\text { Images }\end{array}$ & $\begin{array}{l}\text { (i) Work-site operation manual using } \\
\text { satellite images [13] } \\
\text { (ii) The location of the center of a } \\
\text { typhoon from the satellite } \\
\text { cloud images [14] }\end{array}$ \\
\hline $\begin{array}{l}\text { Microwave } \\
\text { images }\end{array}$ & $\begin{array}{l}\text { (i) Tropical cyclone analysis method } \\
\text { using microwave satellite } \\
\text { Images [15] }\end{array}$ \\
\hline Radar images & $\begin{array}{l}\text { (i) Radar-based typhoon tracking and } \\
\text { monitoring [16] } \\
\text { (ii) Positioning method of a tropical } \\
\text { cyclone center introduced by Wood } \\
\text { [17] and Lee et al. [18] }\end{array}$ \\
\hline $\begin{array}{l}\text { Synoptic surface } \\
\text { observations }\end{array}$ & $\begin{array}{l}\text { (i) Typhoon Committee Operational } \\
\text { Manual [19] }\end{array}$ \\
\hline
\end{tabular}

Forecasting) User Manual [Downloaded at http://www.nrlmry.navy.mil/atcf_web/docs/html/ATCF_UM_Section2.html]) system, the time interpolation is performed using the fixed data determined by a number of sensors and agencies, and a best track is determined by subjective smoothing of this result. Thus, the best track may not be accurate when some data is not received or contradicted. Accordingly, the inconsistency in the actual location of the TC is reduced using the method that provides more weighting of the data with high reliability $[9,10]$. While qualitative, the uncertainty of a best track is expressed as poor, fair, or good depending on the type and source of data. Recently, several studies attempted to determine the center of TC objectively and to automate the process through the development of algorithms. But it was only applied to satellite imagery $[11,12]$.

In general, the TC center is a low level circulation center (LLCC) that is founded in the tropical convection zone. This is because a TC is a short cyclone that is rooted in the lower atmosphere and develops vertically. Therefore, how well the low level circulation appears in the data is an important component of the analysis. The temporal and spatial resolutions of the data are also important because the TC structure can be more clearly analyzed when observation networks are dense, and the change in the structure can be promptly detected when data are frequently received. Finally, the quality of a best track is dependent on the observation altitude and the temporal/spatial resolution. Figure 1 shows the reliability 


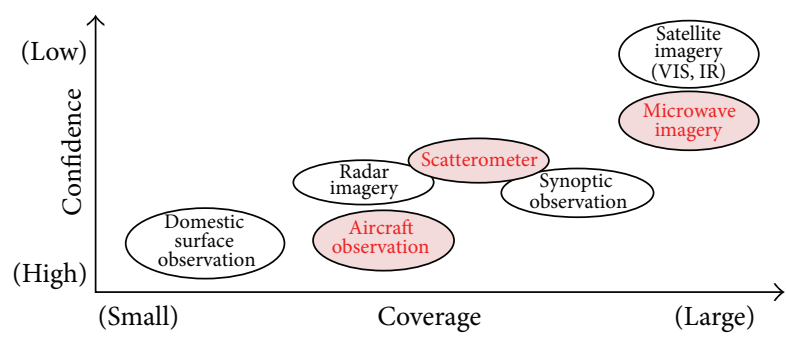

FIgURE 1: Confidence and coverage of individual observations. Synoptic observation refers to the surface observation data from the Regional Basic Synoptic Network (RBSN) in the western North Pacific basin received through GTS (Global Telecommunication System). Shading indicates additional information received later (analysis time).

and coverage of each data based on the aforementioned elements. Considering that the reliability of the data increases when the resolution is high and the frequency of the data acquisition is high, the reliability is on the order of the domestic surface observation (including the AWS of Korea, China, and Japan), aircraft observation, synoptic observation, radar images, scatterometers, microwave images, and visible/infrared images (from highest to lowest). The synoptic observation includes the surface observation data from the Regional Basic Synoptic Network (RBSN) in the western North Pacific basin received via telegram through the Global Telecommunication System (GTS) and ship and buoy data. These data have a relatively low level of confidence due to the observational error caused by a typhoon or due to coarse spatial resolution. Thus, this data was separated from the domestic surface observation.

Finally, the uncertainty of the analysis is closely related to the reliability of data. When the data is precise, the uncertainty generally decreases, and the measurement range also becomes apparent. In this regard, the uncertain range, defined as the TC center for each data, was defined as a potential interval (PI), and the minimum uncertain range was defined as an optimal PI. Subsequently, the PIs of different data (A, B, and C) are assumed to be overlapped, as shown in Figure 2.

If the reliability of the data is in the order of $A>B>C$, Figure 2(a) shows an ideal optimization result where the TC eye is clear or the accuracy of the data is high. In contrast, Figure 2(b) shows a rare case in which the PI of Data B with relatively low reliability is smaller than that of Data A. Figures 2(c) and 2(d) show cases in which the PIs for each data are diverse and the TC eye is not clear. In the situation where various uncertainties are combined, the optimal PI can be described as the intersection of the PIs as shown in the shaded area $[20,21]$.

The optimal PI is ultimately a region in which the TC center is located with the highest probability. To optimize, the PI needs to be narrowed down in the direction of highest probability. Accordingly, data are analyzed from the one with low reliability to the one with high reliability, and there is a premise that the PI of high-level data should be smaller than that of low level data. Consequently, the contradictory case as shown in Figure 2(b) is excluded. When measurement of the highest ranked PI is impossible, the optimization is performed utilizing the second highest ranked PI. For the cases shown in Figures 2(a), 2(c), and 2(d), the range that the PI of the higher rank data occupies in the optimal PI is wider, and thus there are weighting effects.

The optimal PIs obtained from each analysis period based on the aforementioned method provide the boundary conditions for stable smoothing, and the best track is within the optimal PI as shown in Figure 3. The circle and "X" represent the PI for each data and the estimated location of the TC center, respectively; and the shaded area and "." represent the derived PI and the location of the TC center. This study measures the unclear range of data using the PI and quantitatively expresses the uncertainty of the analysis through optimization.

3.2. Basic Stages of the Postanalysis. The institutions that produce the best tracks (e.g., RSMCs, CMA, JTWC, and HKO) have their own analysis procedure, but they undergo a similar process of data collection, postanalysis (after the TC season), and analysis result storage (ATCF User Manual, Figure 7 from [22]). In this study, a postanalysis process with the following five stages was designed based on the analysis method mentioned in Section 3.1 and by including the aforementioned common parts.

Stage 1 (database). Observation data is collected and stored in a database for the postanalysis.

Stage 2 (potential interval). The PI that is estimated to be the location of the TC center is analyzed for each dataset. The PI should be narrowed down depending on the reliability of the data.

Stage 3 (optimization). The optimal PI is determined, and the determined center position values are expressed together.

Stage 4 (smoothing). Smoothing provides the most natural track for the entire path within the optimal PI.

Stage 5 (metadata). The final best track file and the basic data used for the postanalysis are stored in the database.

\section{Postanalysis}

4.1. Determination of a Valid Interval. For the fixed data in Table 1, the PI cannot be obtained because the TC center position has already been determined. However, this data is derived from various reliable methods (e.g., ADT, DVTS, and SATC) and still valuable. However, in this case, each data exhibits different reliabilities, and thus, it is different from the PI introduced earlier. Therefore, the region including the entire fixed data is defined as the valid interval, implying a range in which the analysis is possible.

Figure 4 shows an example of the entire fixed data received via telegram around 00 UTC, June 19, 2013, during the period of the activity of Typhoon LEEPI, and the circle including this represents the valid interval. 


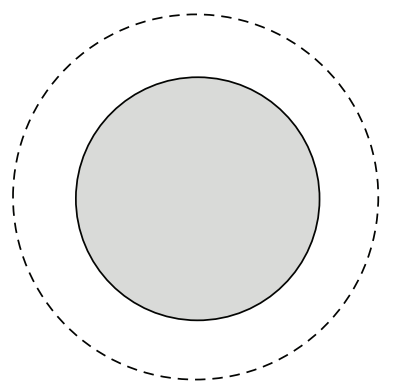

(a)

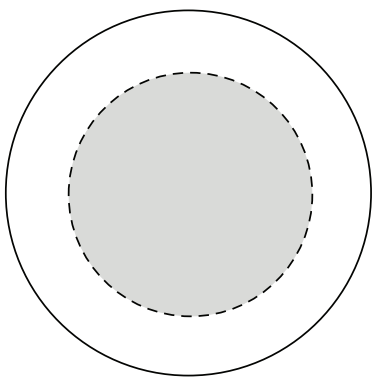

(b)

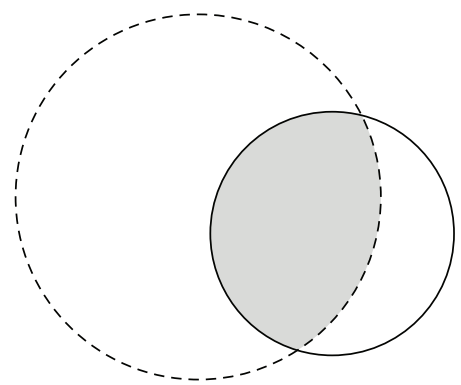

(c)

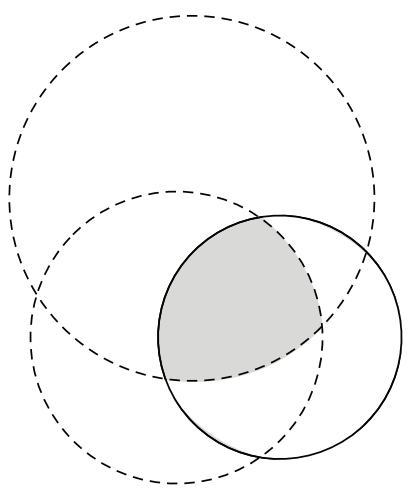

(d)

Figure 2: Overlaying the potential intervals of Data A (solid line), Data B (dashed line), and Data C (long dashed line). Shaded area indicates the optimal potential interval (PI).

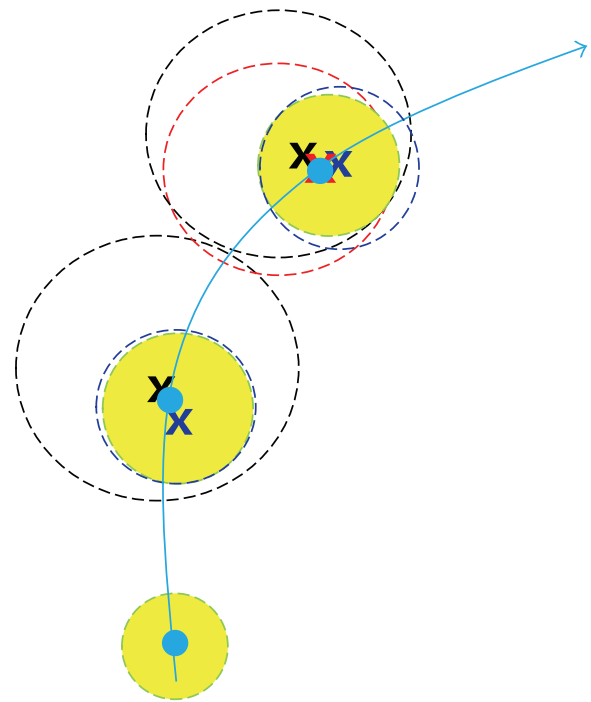

PIs and centers of TC

(X) VIS/IR imagery

(X) Microwave imagery

(X) Radar imagery

Optimal PI and center of TC

FIgURE 3: Conceptual diagram of the optimization method from various potential intervals (PIs). "X" represents the estimated centers of the tropical cyclone from VIS/IR (black), microwave (blue), and radar (red) imagery. The optimal PI is shaded.

4.2. Visible/Infrared Image Analysis. Visible/infrared images are the least limited by time and space; and in the case of COMS images, data can be received every 15 minutes. For the postanalysis using visible/infrared images, the TC center estimation method in the "work-site operation manual using satellite images (2013)" made by KMA was used [13].

The estimation of the PI using visible/infrared images is divided by the Dvorak method depending on the cloud type, and it is performed in the order of (1) the cloud type selection, (2) the center position analysis, and (3) the PI analysis. However, the Dvorak method is estimated based on a single cloud photograph, rather than direct observation, and finding an LLCC through the animated images should be performed together. In particular, when there is CDO (Central Dense Overcast), shear pattern, or a number of convection cells, the reliability of the Dvorak method is low, and determining the rotation center of low level cloud through the animated images has a relatively high accuracy [23]. The cloud scene type is automatically determined by Advanced Dvorak Technique (ADT) on the Web-Based Typhoon Analysis System developed by NMSC/KMA and, later, manually adjusted by using DVTS (subjective Dvorak technique). Most typhoon operation agencies from other countries also decide the cloud type of TC by using ADT and DVTS.

The determination of the PI was performed following the Accuracy of Center (ACC) mensuration in the manual. The ACC represents a range that includes about $90 \%$ of the estimated multiple center positions, which was used as the PI. Figure 5 shows an example where the PI and the location of the TC center have been obtained using infrared and visible imagery for the same time as that in Figure 4. The cloud type for the corresponding time exhibited a band pattern. The middle of the line that connects the head of the band to the warm sector ending point was determined as the TC center position, and the smallest circle that is determined by the curvature of the band axis was given as the PI.

4.3. Microwave Image Analysis. Microwave images are difficult to use for real-time analysis because of the lag in acquisition time, but they have the greatest utility during the postanalysis because there is no spatial limitation and the TC internal structure, which is difficult to analyze using only infrared/visible images, can be easily examined. However, it is necessary to analyze each wavelength band during microwave image analysis.

High frequency band images generally have good resolution, but the range of the TC eye is wide and the parallax error is large because the observation is made at a high altitude. In contrast, for low frequency band images, the parallax error is small, and the range of the TC eye is narrow because the observation is made at a low altitude. However, the range of 


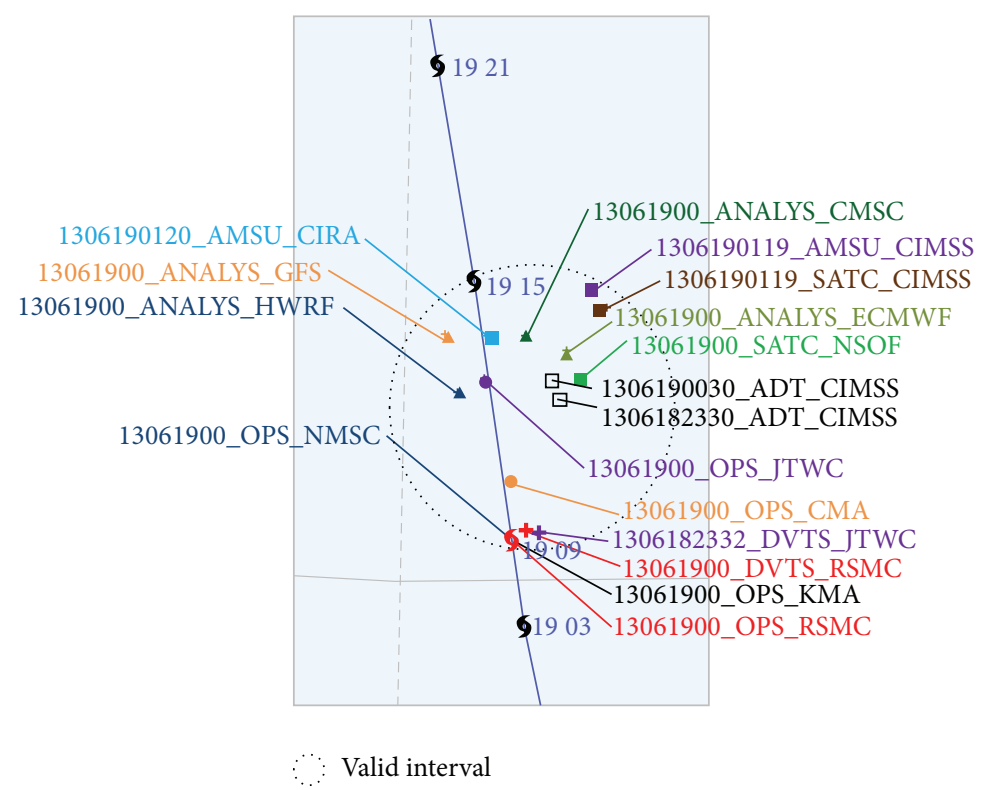

FIGURE 4: Overlaying the fixed data (markers) and the valid interval (circle) on track chart at 00 UTC on 19 June, 2013, for Typhoon LEEPI (1304). Each fixed data (marker) comes in different color and shape with each text. It was written in the form as the detected date_the name of used data or imager_the name of agency. Please refer to the list of abbreviations in Table 1. The red and black typhoon symbols denote the center positions at $00 \mathrm{UTC}$ on 19 June and other times.

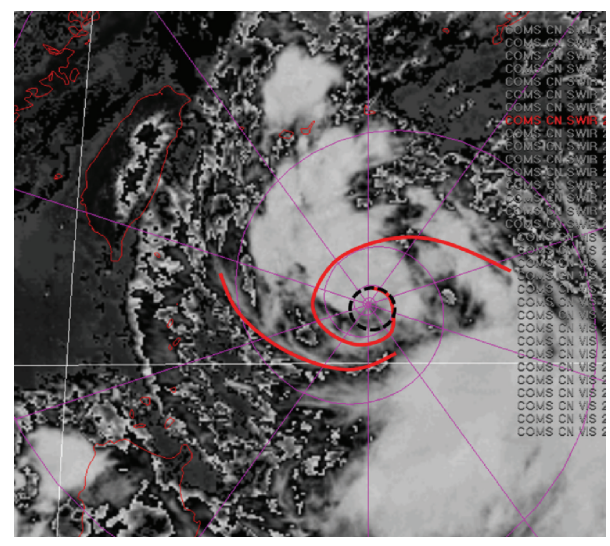

(a)

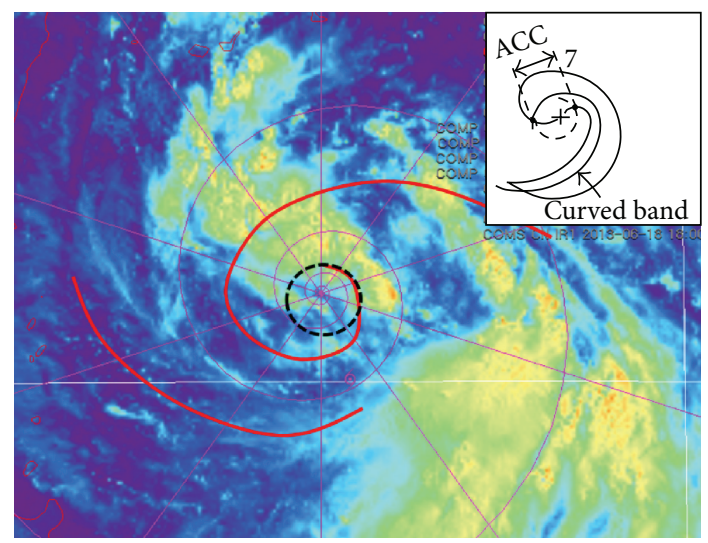

(b)

FIGURE 5: The PIs (circles) and the estimated centers (dots) of Typhoon LEEPI (1304) using shortwave infrared (a) and visible imagery (b) of satellite "COMS," at the same time as Figure 4. The schematic diagram on the top right shows estimation of a TC center and ACC (or a range similar to PI) of a band pattern cloud and was excerpted from the manual.

the TC eye is unclear. Therefore, by comparing between high and low frequency band images, a more accurate analysis of the location of the TC center can be made.

The TC center position and the PI estimation method are different depending on the cloud type, which is similar to the visible/infrared images, and it is performed in the following order: (1) cloud type selection, (2) center position analysis, (3) PI analysis for each wavelength band, and (4) PI adjustment through comparison. For the microwave images, there is a "TC eye analysis size" measurement method, which was determined as the PI, and has the same meaning as in ACC.
When the image results are different at a specific frequency band, the PI of a low frequency band image with a small parallax effect is determined. If the results are unclear, a final decision is made based on the high frequency band image. When there is no microwave image for a specific analysis time, the PI is determined from a simple interpolation of the data taken at the closest time. For a detailed analysis, refer to the "tropical cyclone analysis method using microwave satellite images [15]." Figure 6 shows examples where the PI and the TC center position have been obtained using a microwave image for the same time as that in Figure 4, which represent the $91 \mathrm{GHz}$ and $37 \mathrm{GHz}$ images, respectively. 


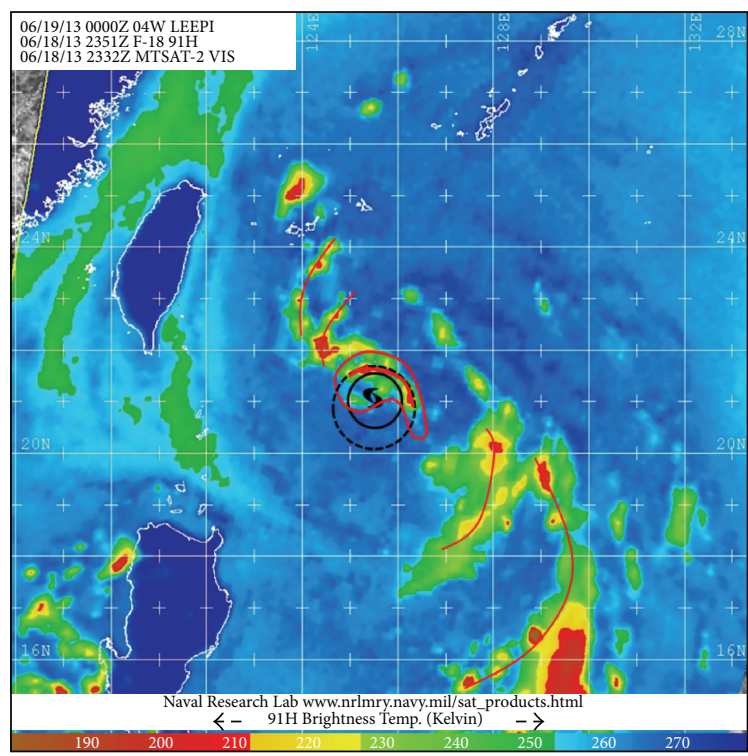

(a)

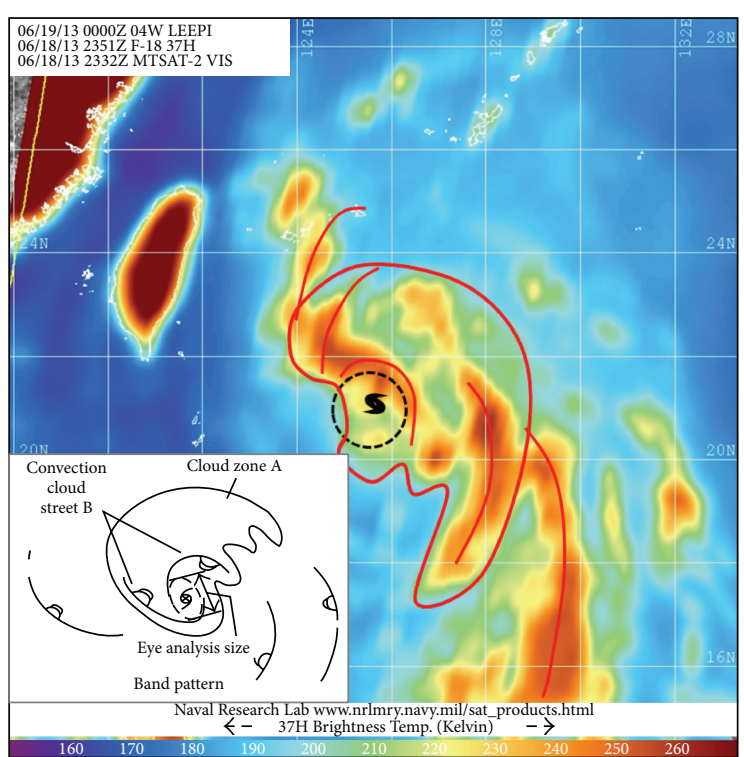

(b)

Figure 6: The same as Figure 5, but with respect to microwave imagery: (a) $91 \mathrm{GHz}$ and (b) $37 \mathrm{GHz}$. Solid circle means the optimal PI. The schematic diagram on the bottom left shows estimation of a TC center and eye analysis size (or a range similar to PI) of a band pattern cloud and was excerpted from the manual.

The center position and the PI were determined by comparing the cloud area of low luminance temperature in the $91 \mathrm{GHz}$ image and the cloud area of high luminance temperature in the $37 \mathrm{GHz}$ image.

In the case of sea surface wind data, the center of rotation was defined as the position of the TC eye, and the circle whose diameter is the long axis of the smallest circle determined by the curvature was defined as the PI. Sea surface wind data are generally useful for the analysis of TC intensity and strong wind radius, but when the intensity is weak, the accuracy of the center position analysis is low, and thus it is desirable to compare it with other satellite images (e.g., visible, infrared, and microwave images) $[24,25]$.

4.4. Radar Image Analysis. Radar images are highly useful and have higher temporal and spatial resolution than satellite images. However, when the TC rotation structure is collapsed or a TC is very close to radar, it is difficult to perform a TC center analysis. The images that are necessary for postanalysis are the corrected reflectivity (CZ) and radial velocity (VR). Postanalysis is performed by adjusting the center position and the PI by comparing them. There are also various TC center determination methods (e.g., dual wind field, vertical cross section, and echo top); and for a detailed analysis method, refer to the "Radar-based typhoon tracking and monitoring [16]".

The PI was defined as a circle whose diameter is the long axis of an empty area where a radial velocity line of 0 passes and there is no echo. When there was a difference between other radar images, the PI was defined as a circle whose diameter is the long axis of the smallest circle. Figure 7 shows an example of the analysis of the PI and center position using radar images. Figures 7 (a) and 7(b) represent the radial velocity and echo top synthetograph, respectively. For the same time as that in Figure 4, the typhoon stayed outside the range that is covered by radar. Thus, the analysis results for the time when Typhoon DANAS had been close to Jeju Island (06 UTC, October 8, 2013) were presented.

4.5. Synoptic Observation Data Analysis. The telegram data received through GTS are mostly direct observational data and includes synoptic and ship observations. They have high accuracy but are relatively sparse. Thus, the PI is estimated following the center position determination method based on wind and sea level pressure in the "Typhoon Committee Operational Manual [19]".

The PI determination method includes the inflow angle method, the circular center method, and the distance intersection method, which are chosen depending on each situation. All of these methods lead to a region where more than three lines intersect, and a circle whose diameter is this region is determined as the PI. If a calculation is possible based on all of the three methods, the smallest circle is used as the PI. Figure 8(a) shows an example where the PI of the typhoon was obtained using the inflow angle method for the same time as that in Figure 4, and Figure 8(b) shows the schematic diagram of the inflow angle method. However, for the corresponding time, there were relatively few ocean data, and thus an intersection region was not formed as shown in Figure 8(b). This is an exceptional case in which the PI measurement is impossible, and the corresponding data is excluded. 


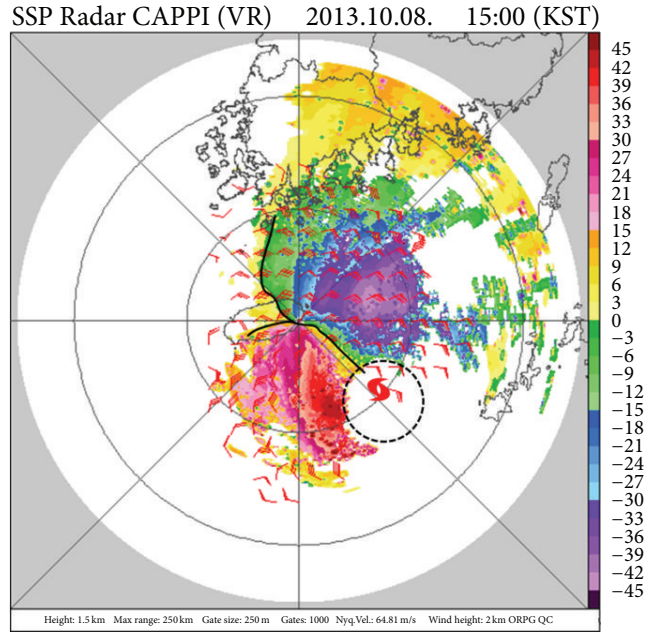

(a)

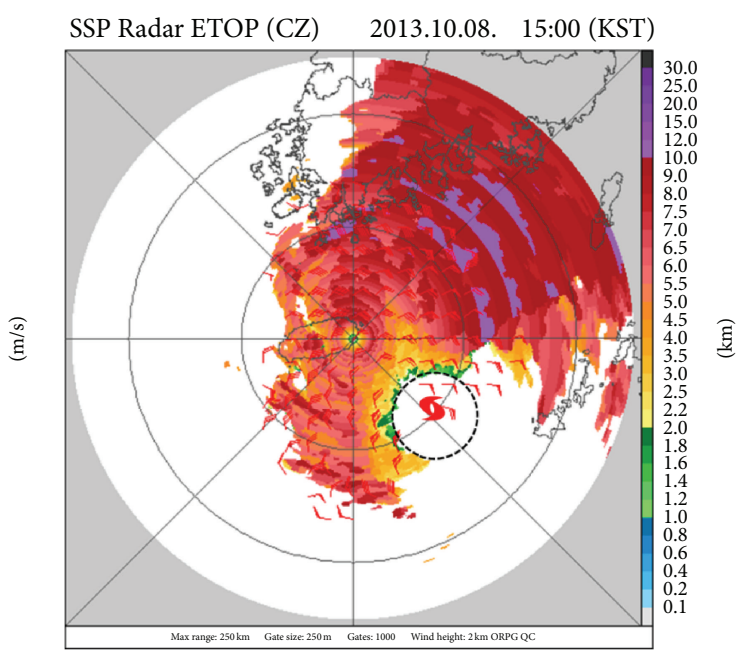

(b)

Figure 7: The PIs (circles) and the estimated centers (markers) of Typhoon DANAS (1324) at 06 UTC October 8, 2013, using radar imagery from KMA: CAPPI (VR) (a) and echo top (CZ) (b).

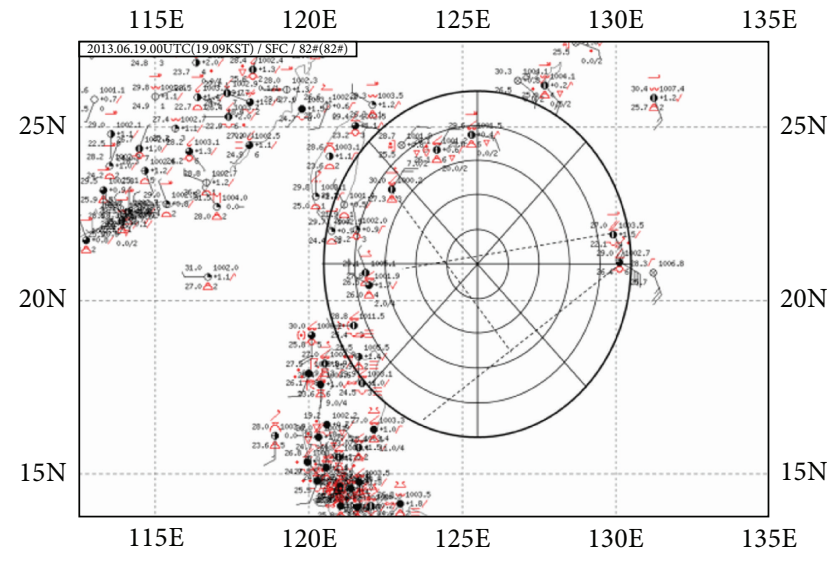

(a)

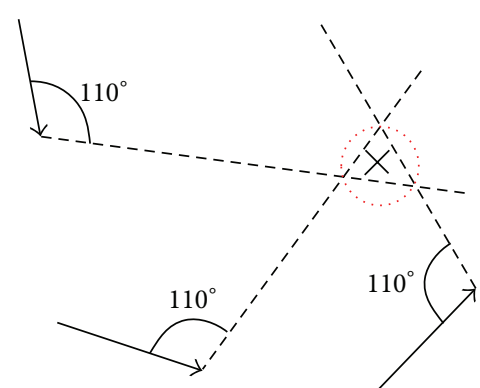

(b)

FIGURE 8: The same as Figure 5, but with respect to postanalysis of (a) the synoptic map from RBSN and (b) the decision of PI (circles) using inflow angle method. The latter is the same as Figure 3-C.3 from WMO [19].

4.6. Analysis of the Observation Data in Korea. Observational data in Korea has the highest accuracy because observation networks, both on land and at sea, are densely distributed and thus increase the data resolution. The observations have been standardized, and data are received at five-minute intervals [26]. However, the definite TC positioning could be difficult due to the topography and observation error caused by a typhoon. Thus, the PI is estimated by obtaining the lowest sea level pressure and wind convergence range using sea level pressure and a wind distribution map. Also, The PI is adjusted by tracking the time at which the lowest points of sea level pressure and wind speed have been passed, based on the time series of nearby observation spots. Figure 9 shows an example of the analysis of the PI and center position using the observation data in Korea during the landfall of Typhoon SANBA in 2012 (08 UTC, September 17, 2012). (No typhoon made landfall in Korea in 2013. This study aimed to propose a PI analysis method by using available data and it was meaningful in that it introduced an analysis method for domestic surface observation data even if it was "discussing examples not from three typhoons in 2013.") Figures 9(a) and 9(b) represent the wind vector and sea level pressure distribution, respectively.

\section{Determination of a Best Track}

In Stage 3 (optimization), all of the TC center positions and PIs estimated for each data in Section 4 are expressed in one chart. Subsequently, the minimum range where the PIs overlap is determined as the optimal PI, following the method mentioned in Section 3.1. Figure 10 shows the overlapping of the PIs obtained through the valid interval, visible images, and microwave images obtained in Section 4, and the shaded range represents the optimal PI. Therefore, 


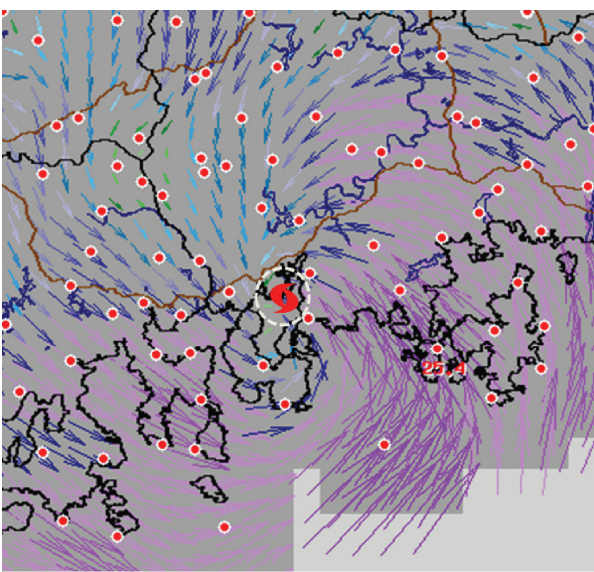

(a)

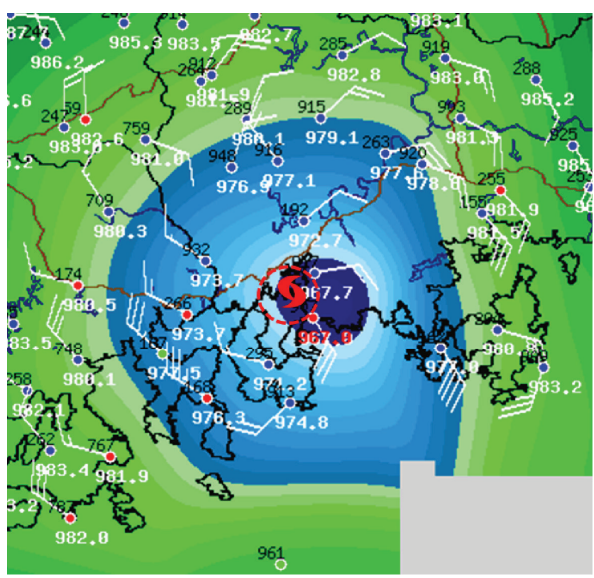

(b)

Figure 9: The PIs (circles) and the estimated centers (markers) of Typhoon SANBA (1216) at 06 UTC 17 September, 2012, using domestic synoptic data (including AWS): (a) wind vector and sea level pressure (SLP) (b).

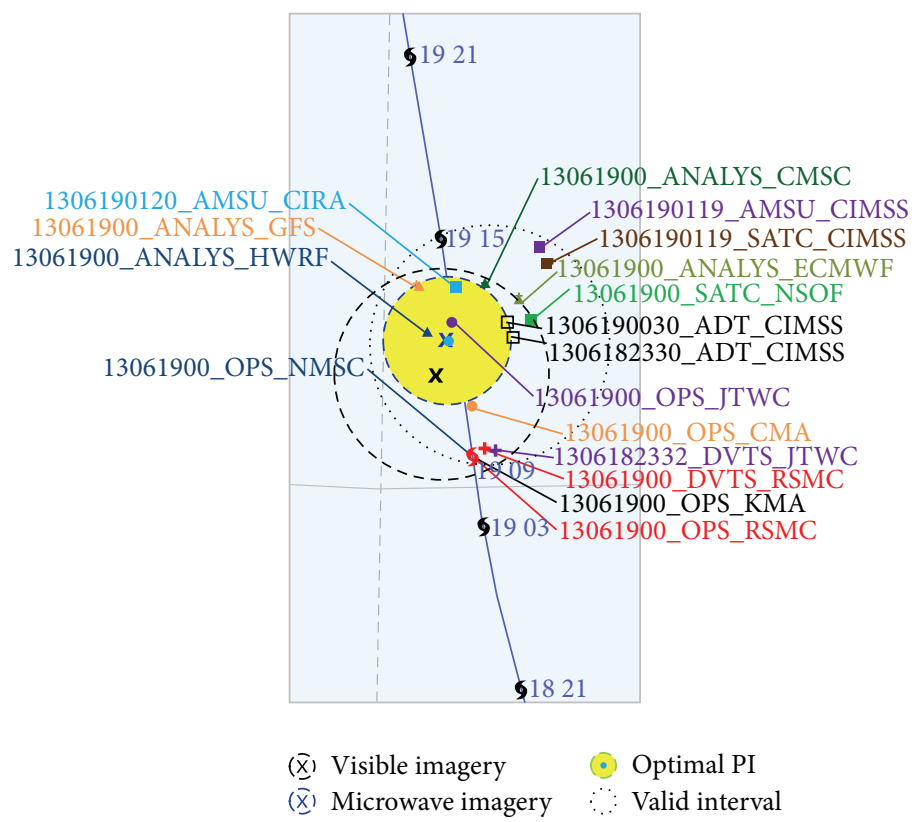

FIGURE 10: Overlaying the PIs and the valid interval on track chart at 00 UTC on 19 June, 2013, for Typhoon LEEPI (1304). "X” represents the estimated centers of the tropical cyclone from visible (black) and microwave (blue) imagery. The optimal PI is shaded.

the radar images and synoptic observation data were excluded because estimation of the PI was impossible.

In Stage 4 (smoothing), smoothing among TC center positions is performed for each analysis time and in principle, smoothing is conducted within the PIs. Consistency is checked by overlapping the smoothed center position with the synoptic condition, cyclone tracking on a weather map, and steering current. The final best track is determined by adjusting within the PIs. Until Stage 3, the PI center is possibly the best track. However, in Stage 4, after smoothing and consistency checking, the final best track may not be the PI center. Smoothing is a process in which three TC centers are used to create a natural route and the final TC center may not correspond to the PI center. And in the latter step (consistency checking), an overall adjustment stage, only the minimum subjective decision of the analyst is allowed. This counters errors in automatic analysis, and so forth.

To simply verify the best track obtained by the method suggested in this study, differences in the locations between the real-time analysis for the postanalysis period of Typhoons LEEPI, KONG-REY, and DANAS and the best tracks from JTWC and RSMC are obtained as shown in Figure 11. Here, K (B-O), K-R, and K-J represent the differences in the distance between the best track calculated in this study and the KMA real-time analysis, RSMC best track, and JTWC best track, respectively; and R-J represents the difference in the distance 

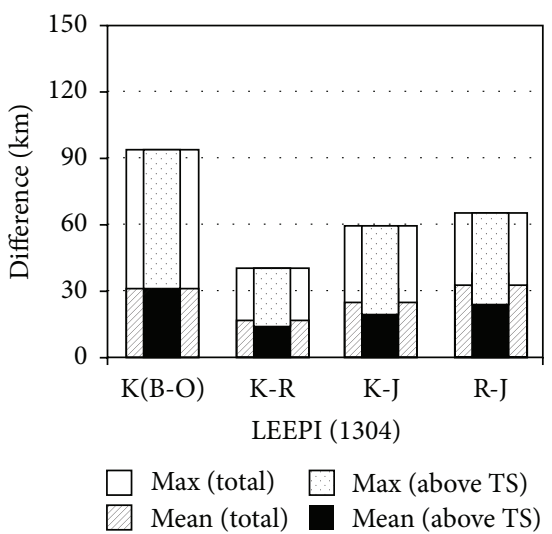

(a)

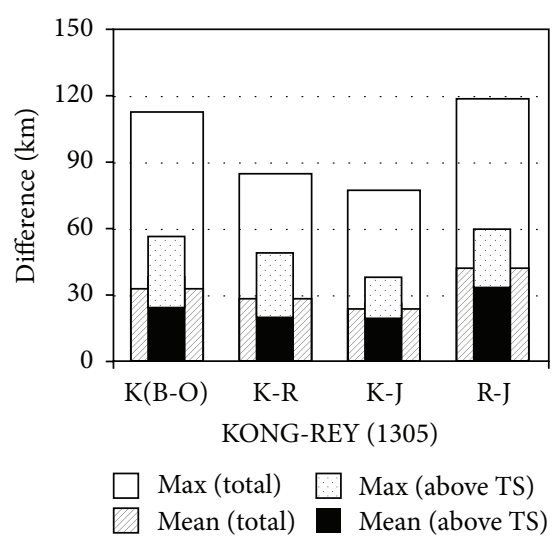

(b)

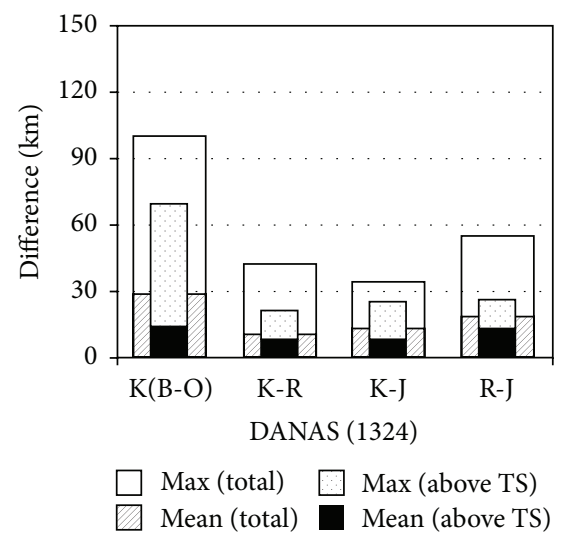

(c)

FIGURE 11: Differences $(\mathrm{km})$ in the position of the TC center between KMA best tracks $(\mathrm{B})$ and real-time operations $(\mathrm{O})$ and among best tracks from KMA (K), RSMC (R), and JTWC (J) for Typhoon LEEPI (1304), KONG-REY (1315), and DANAS (1324). Here "above TS" denotes the differences in the TCs categorized as a tropical storm or above.

between the best tracks of RSMC and JTWC. The thick bar represents the maximum and average differences in the distance between the best tracks for the entire intensity including tropical depression, and the thin bar represents the maximum and average difference in the distance between the best tracks at the tropical storm or more intensity (the maximum wind speed near the center is more than $17 \mathrm{~m} / \mathrm{s}$ ). To determine the difference between the TC center positions, a method that obtains the latitudinal and longitudinal distances between two spots using the haversine formula equation suggested by Chang et al. [3] was used. To calculate the best track, the TC center position was adjusted by about $30 \mathrm{~km}$ on average (tropical storms or above) and by up to about $100 \mathrm{~km}$ (total) after the postanalysis, based on the difference from the realtime status analysis. Except for Typhoon LEEPI, the cases that did not exhibit a tropical depression showed a smaller difference between the real-time status analysis and the best track for each institution compared to those cases that include tropical depression, which indicates that the uncertainty of the analysis was large in the case of tropical depression with a relatively low intensity. Also, the typhoon that showed the maximum difference $(94 \mathrm{~km})$ from the real-time analysis at a tropical storm or more intensity was Typhoon LEEPI, and the corresponding time was at 00 UTC, June 19, 2013. The postanalysis for this was described in Section 4. Realtime analysis was performed using only visible and infrared images, and two convection cells were dispersed and the low level circulation center was not clear as shown in Figure 5. Thus, the middle of the two cells at that time was determined as the TC center. However, based on the analysis of the microwave images obtained later, the TC center position was adjusted toward the north compared to that in the realtime analysis, as shown in Figure 6. Thus, there was a large difference from the real-time analysis.

Both the average and maximum differences between the best tracks of the three institutions (KMA, JTWC, and RSMC) were in the following order: KMA-RSMC $<$ KMAJTWC $<$ JTWC-RSMC. The average differences between
Korea and other institutions for all of the typhoons were less than $30 \mathrm{~km}$ (the maximum value was $78 \mathrm{~km}$ between KMA and RSMC for Typhoon KONG-REY), which was smaller than the differences between JTWC and RSMC (the average was less than $41 \mathrm{~km}$; the maximum value was $119 \mathrm{~km}$ between JTWC and RSMC for Typhoon KONG-REY). This difference was much smaller than those in the results of Song et al. [27] and Lowry [4], which compared the differences in the position between the best tracks of each institution over a long period (more than 50 years), indicating that relatively stable results could be obtained.

Figure 12 compared best tracks calculated based on the postanalysis and best tracks of JTWC and RSMC. Optimal PI of every 6-hourly point (different analysis time) was presented in two shades. In WMO [19], the uncertainty in the distance from the center is expressed as good (below $55 \mathrm{~km}$ ), fair (55-110 km), and poor (above $110 \mathrm{~km}$ ) depending on the radius from the TC center. In this study, the different shades of colors were used to describe the radius of PI. The periods with large PI include the initial stage of TC development, the weakening stage [5], and the period of interaction with the land [6]. These were similar to the periods where TC position analysis had been relatively difficult in previous studies. Also, the difference between the best tracks was generally large in the initial stage of development and the weakening stage, except for around 00 UTC, June 9, when Typhoon LEEPI was active. Therefore, the optimal PI proposed in this study can mean accuracy in postanalysis, and (as explained in Figure 2 and Section 3.1) the typhoon center location determination may be reasonable, from the perspective of probability.

\section{Summary}

In this study, a postanalysis method was proposed to obtain a reasonable calculation of a best track. The postanalysis process was designed into five basic stages: database, potential interval, optimization, smoothing, and metadata. Furthermore, the analysis methods for each stage were introduced. 


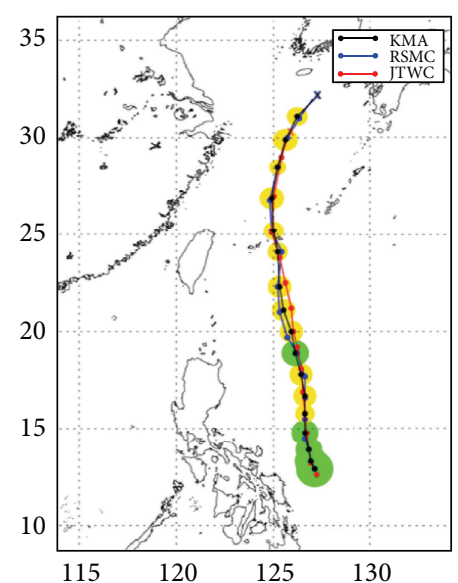

(a)

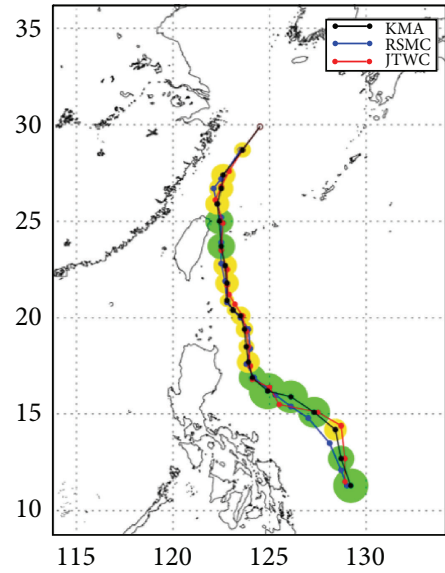

(b)

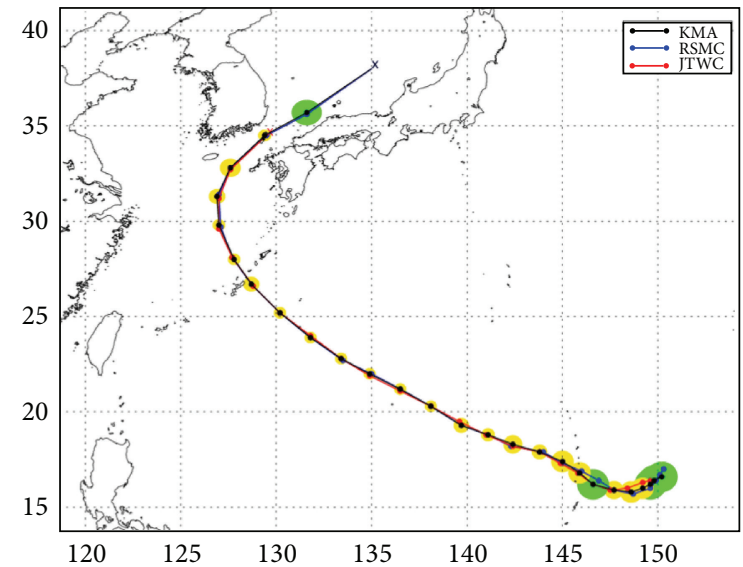

(c)

Figure 12: Best tracks for (a) Typhoon LEEPI (1304), (b) KONG-REY (1315), and (c) DANAS (1324) from RSMC, JTWC, and KMA. Shading denotes the optimal PI of KMA. Yellow and green imply less than $55 \mathrm{~km}$ and $55-110 \mathrm{~km}$ as the radius of PI.

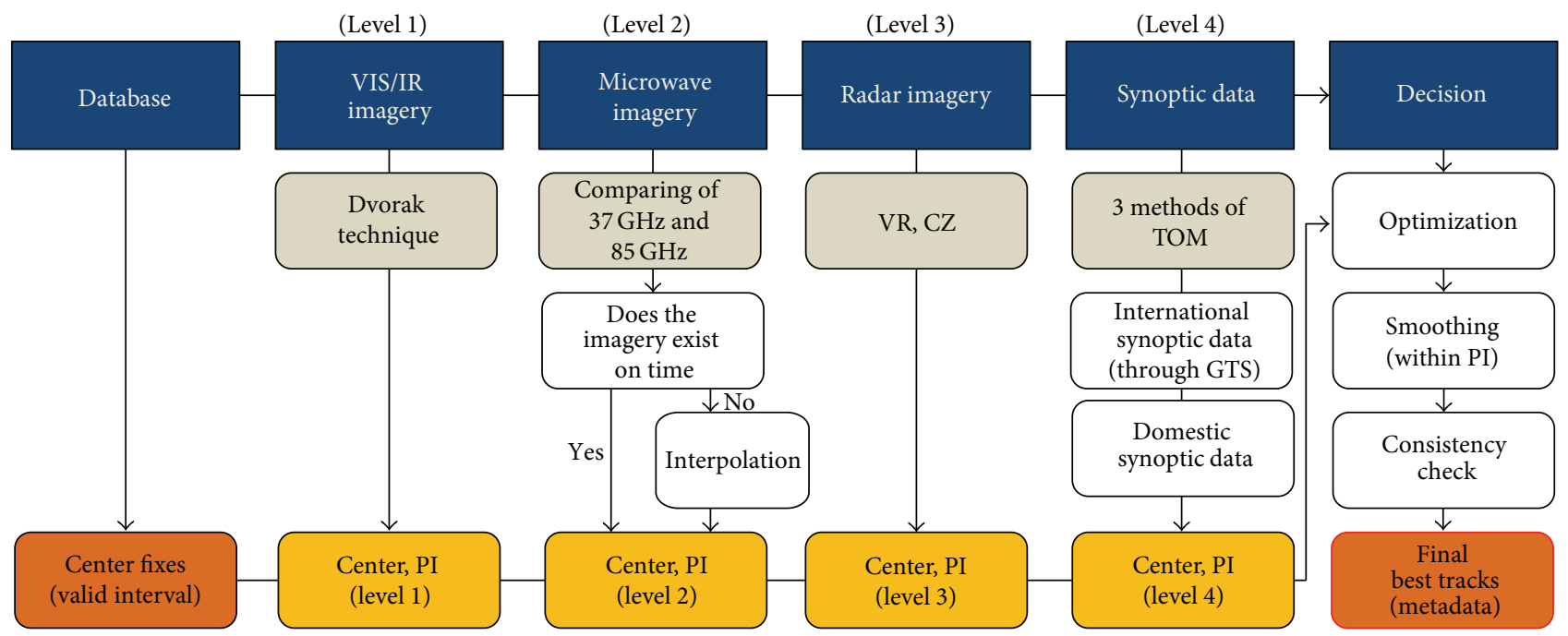

FIGURE 13: Flowchart of the tropical cyclone center positioning for producing the best tracks.

In Stage 2 (potential interval), we introduced the "potential interval," which is the minimum unit for adjusting the TC center position, and a method for obtaining this using the existing analysis method for each data was suggested. In Stage 3 (optimization), the optimal PI was obtained based on the differential application of the range depending on the reliability of the data (i.e., intersection of PIs depending on the priority). This expresses the uncertainty of the data and also serves as a guide for smoothing. Figure 13 shows the schematic diagram of the best track determination suggested in this study. The level represents the reliability of the data, and higher priority is placed as the level increases. This flowchart will be the basis of the best tracking system developed by KMA, and the system will be designed so that the PI can be automatically established following the analysis method for each data. The method using PIs, which was introduced in this study, can reduce uncertainty of best tracks but involve a large quantity of analysis data and complex process, requiring a significant amount of time. Therefore, it is necessary to reduce analysis time by using an automated process for determining the cloud type, PI, and TC center, and the results will not vary much between different analysts.

Furthermore, we are planning to build the system so that the analyst can manually adjust results that were automatically produced (by using consistency check in Figure 13). Therefore, the automated process is only intended to reduce analysis time and produce reliable results and does not exclude final subjective decisions. In other words, this system minimizes subjective decision made by the analyst.

For verification, test calculations of the best tracks of three typhoon cases that had affected Korea in 2013 (LEEPI, KONG-REY, and DANAS) were performed following the suggested postanalysis method, and the results were compared with those of JTWC and RSMC. As a result, the region with a relatively wide range in optimal PI was consistent with the period where determination of the low level circulation 
center was difficult, and it was also similar to the period where the difference between the best tracks was large. Moreover, the difference in the best track from the other two institutions was small, indicating that unless jagged data could be obtained.

However, for all of the aforementioned cases, the typhoon did not make landfall in the Korean Peninsula, and thus the use of ground observation data with high accuracy was small. Also, as aircraft observations were not included, a complete verification was difficult. Nevertheless, this study proposed a method that determines an optimal TC center position considering uncertainty when data are insufficient or determination of the center position is difficult. This postanalysis process is necessary because a TC spends most of its life on the sea or cases with poor visibility are common.

For the postanalysis of the intensity and size of a typhoon, the five basic stages suggested in this study are also applied. However, as there are differences in each major analysis data, it is necessary to design a detailed process considering this as shown in Figure 13. Currently, the KMA is developing a method that expresses the reliability and uncertainty of the data for each analysis element and is planning to officially produce best tracks from 2016 through the operation of a system using the developed method. In that sense, the typhoon positioning is at the important preliminary step for the production of the formal best track data with typhoon intensity.

\section{Abbreviations}

ACC: Accuracy of Center

ADT: $\quad$ Advanced Dvorak Technique [28]

AMSU: Advanced Microwave Sounding Unit

ASCAT: Advanced scatterometer

AWS: Autoweather System

CIMSS: Cooperative Institute for Meteorological Satellite Studies

CIRA: Cooperative Institute for Research in the Atmosphere

CMA: China Meteorological Administration

CMSC: Canadian Meteorological Centre's Global Prediction Model

COMS: Korea's Communication, Ocean, and Meteorological Satellite

CZ: $\quad$ Corrected Radar Reflectivity

DVTS: Subjective Dvorak technique

ECMWF: European Center for Medium Range Weather Forecasts' Global Prediction Model

GFS: Global Forecast System (produced by NCEP)

HKO: Hong Kong Observatory

HWRF: Hurricane Weather Research and Forecasting model (produced by NCEP)

JTWC: Joint Typhoon Warning Center

KMA: Korea Meteorological Administration

NESDIS: National Environmental Satellite, Data, and Information Service

NMSC: National Meteorological Satellite Center, KMA

NSOF: NOAA Satellite Operations Facility

OPS: Real-time operations
OSCAT: OceanSat scatterometer

PI: Potential interval

RSMC: Regional Specialized Meteorological Center

SATC: Satellite consensus

TOM: Typhoon Committee Operational Manual

VR: Radar Radial Velocity

WindSat: Space-born polarimetric microwave radiometer

WMO: World Meteorological Organization.

\section{Competing Interests}

The authors declare that they have no competing interests.

\section{Acknowledgments}

This research is supported by the project "Research and Development for KMA Weather, Climate, and Earth system Services (NIMS-2016-3100)" funded by KMA.

\section{References}

[1] K. R. Knapp, M. C. Kruk, D. H. Levinson, H. J. Diamond, and C. J. Neumann, "The international best track archive for climate stewardship (IBTrACS)," Bulletin of the American Meteorological Society, vol. 91, no. 3, pp. 363-376, 2010.

[2] J. D. Martin and W. M. Gray, "Tropical cyclone observation and forecasting with and without aircraft reconnaissance," Weather and Forecasting, vol. 8, no. 4, pp. 519-532, 1993.

[3] K. H. Chang, W. Lee, M. Lim et al., "Case study on the difference of the analyzed typhoon positions of Major Typhoon Center," Journal of Climate Change and Environment, vol. 1, pp. 51-56, 2013.

[4] M. R. Lowry, Developing a unified superset in quantifying ambiguities among tropical cyclone best track data for the Western North Pacific [M.S. thesis], Florida State University, 2009.

[5] R. D. Torn and C. Snyder, "Uncertainty of tropical cyclone besttrack information," Weather and Forecasting, vol. 27, no. 3, pp. 715-729, 2012.

[6] V. F. Dvorak, “Tropical cyclone intensity analysis using satellite data," NOAA Tech. Rep. 11, 1984.

[7] V. F. Dvorak, A Workbook on Tropical Clouds and Cloud Systems Observed in Satellite Imagery: Tropical Cyclones, vol. 2, 1995, NOAA/NESDIS, 5200, 20333.

[8] A. Burton and C. Velden, "General summary of the work of the workshop (final report)," in Proceedings of the International Workshop on Satellite Analysis of Tropical Cyclones, WMO, Honolulu, Hawaii, USA, 2011.

[9] C. W. Landsea and J. L. Franklin, "Atlantic hurricane database uncertainty and presentation of a new database format," Monthly Weather Review, vol. 141, no. 10, pp. 3576-3592, 2013.

[10] C. Sampson and P. Kathryn, "Objective best track algorithm description,” 2011, http://www.nrlmry.navy.mil/atcf_web/.

[11] A. J. Wimmers and C. S. Velden, "Objectively determining the rotational center of tropical cyclones in passive microwave satellite imagery," Journal of Applied Meteorology and Climatology, vol. 49, no. 9, pp. 2013-2034, 2010.

[12] A. J. Wimmers and C. S. Velden, "Integration of an objective, automated TC center-fixing algorithm based on multispectral 
satellite imagery into NHC/TAFB operations," Mid-Year Progress Report (Year 2), Joint Hurricane Testbed, 2014, http://www .nhc.noaa.gov/jht/13-15reports/JHT_Wimmers_midYear2.pdf.

[13] KMA, "Work-site operation manual using satellite images," Technical note, National Meteorological Satellite Center of Korea Meteorological Administration, 2013.

[14] A. S. Suh, K. L. Kim, C. K. Lee, and M. S. Lee, "The location of the center of a typhoon from the satellite cloud images," Journal of the Korean Meteorological Society, vol. 28, pp. 333-346, 1992.

[15] KMA, "Tropical cyclone analysis method using microwave satellite images," Technical Note, Korea Meteorological Administration, National Typhoon Center, 2009.

[16] KMA, "Radar-based typhoon tracking and monitoring," Weather Radar Center of Korea Meteorological Administration Technical Note WRC2010-03, 2010.

[17] V. T. Wood, "A technique for detecting a tropical cyclone center using a Doppler radar," Journal of Atmospheric \& Oceanic Technology, vol. 11, no. 5, pp. 1207-1216, 1994.

[18] W. C. Lee, J. D. Jou Ben, P. L. Chang, and S. M. Deng, "Tropical cyclone kinematic structure retrieved from singleDoppler radar observations. Part I: interpretation of Doppler velocity patterns and the GBVTD technique," Monthly Weather Review, vol. 127, pp. 2419-2439, 1999.

[19] WMO, "Typhoon Committee operational manual-meteorological component," WMO/TD-No 196, 2013.

[20] J. Marshall, "Spatial uncertainty in line-surface intersections with applications to photogrammetry," in ISPRS Annals of the Photogrammetry, Remote Sensing and Spatial Information Sciences, Volume 1-2. XXII ISPRS Congress, Melbourne, Australia, 2012.

[21] L. E. Ghaoui, Hyper-Textbook: Optimization Models and Applications, MathWorks, Natick, Mass, USA, 2014, https://inst.eecs .berkeley.edu/ ee127a/book/login/index.html.

[22] M. Ying, W. Zhang, H. Yu et al., "An overview of the China meteorological administration tropical cyclone database," Journal of Atmospheric and Oceanic Technology, vol. 31, no. 2, pp. 287-301, 2014.

[23] A. Tsuchiya, T. Mikawa, and A. Kikuchi, "Method of distinguishing between early stage cloud systems that develop into tropical storms and ones that do not," Geophysical Magazine Series 2, vol. 4, no. 1-4, pp. 49-59, 2001.

[24] H. D. Cobb, R. Knabb, P. S. Chang, and Z. Jelenak, "Preliminary assessment of the utility of ASCAT ocean surface vector wind (OSVW) retrievals at the Tropical Prediction Center/National Hurricane Center," in Proceedings of the 28th Conference on Hurricanes and Tropical Meteorology, 15B.4, American Meteorological Society, Orlando, Fla, USA, 2008.

[25] R. T. Edson, "Comparisons and evaluations between the oceansat-2 (OSCAT) and ASCAT scatterometers over tropical cyclones," in Proceedings of the 31st Conference on Hurricanes and Tropical Meteorology, 1.37 pages, American Meteorological Society, San Diego, Calif, USA, March-April 2014.

[26] KMA, The Present and Future Outcomes for Standardization of Meteorological Observations, Separately and Together, Korea Meteorological Administration, 2012.

[27] J.-J. Song, Y. Wang, and L. Wu, "Trend discrepancies among three best track data sets of western North Pacific tropical cyclones," Journal of Geophysical Research Atmospheres, vol. 115, no. 12, Article ID D12128, 2010.

[28] T. L. Olander, C. Velden, and M. A. Turk, "Development of the Advanced Objective Dvorak Technique (AODT)-current progress and future directions," in Proceedings of the 25th Conference on Hurricanes and Tropical Meteorology, American Meteorological Society, San Diego, Calif, USA, May 2002. 

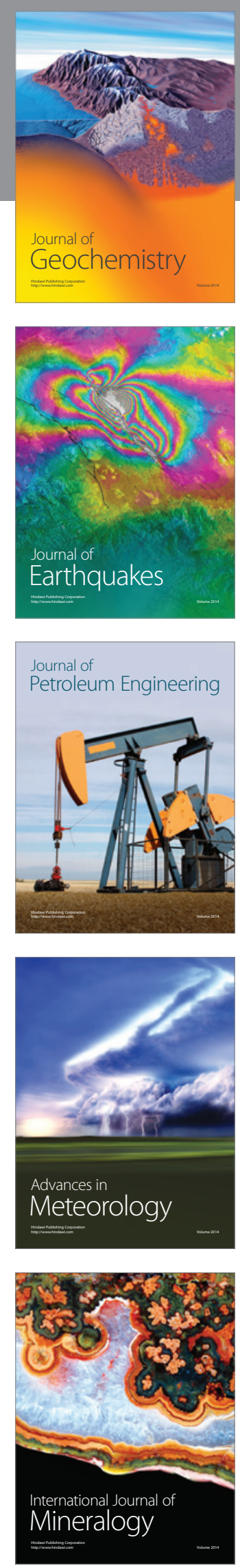
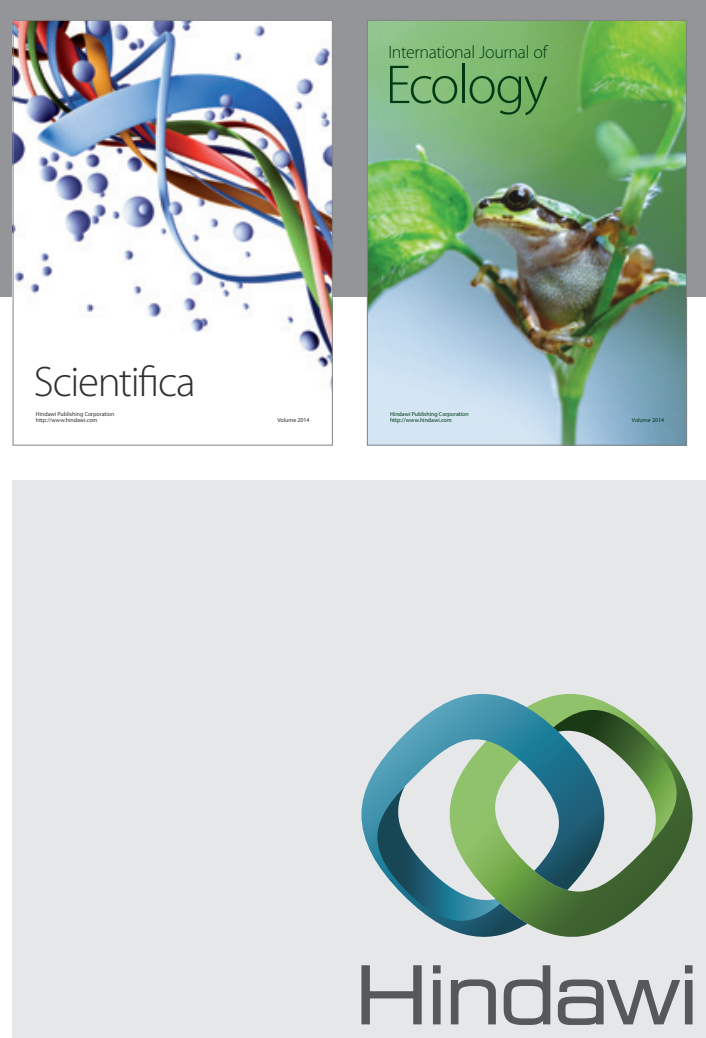

Submit your manuscripts at

http://www.hindawi.com
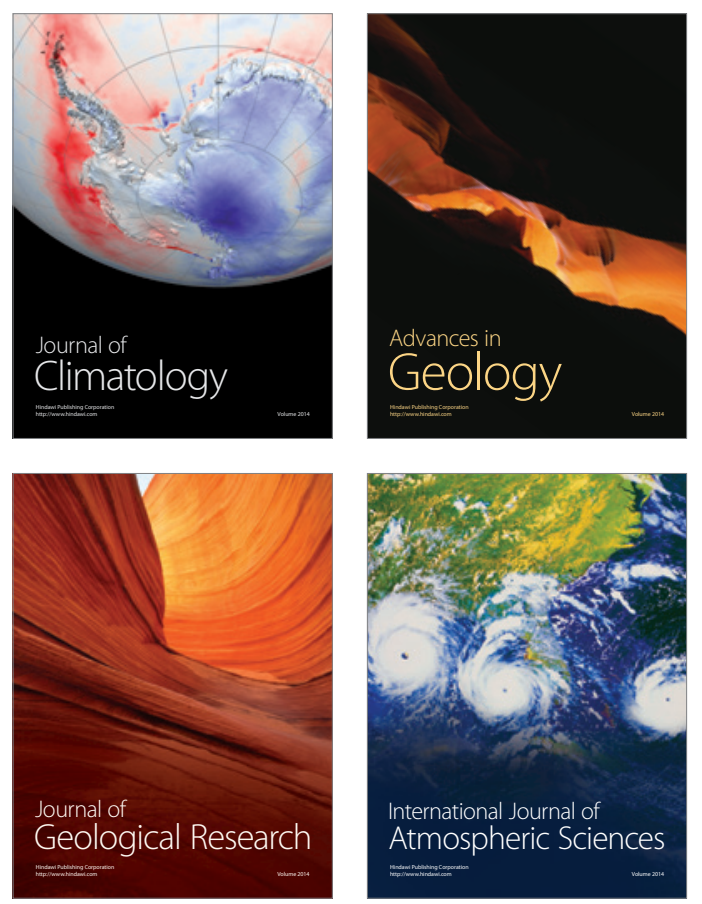

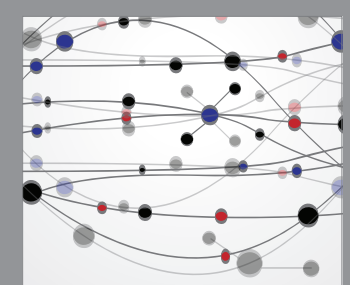

The Scientific

\section{World Journal}
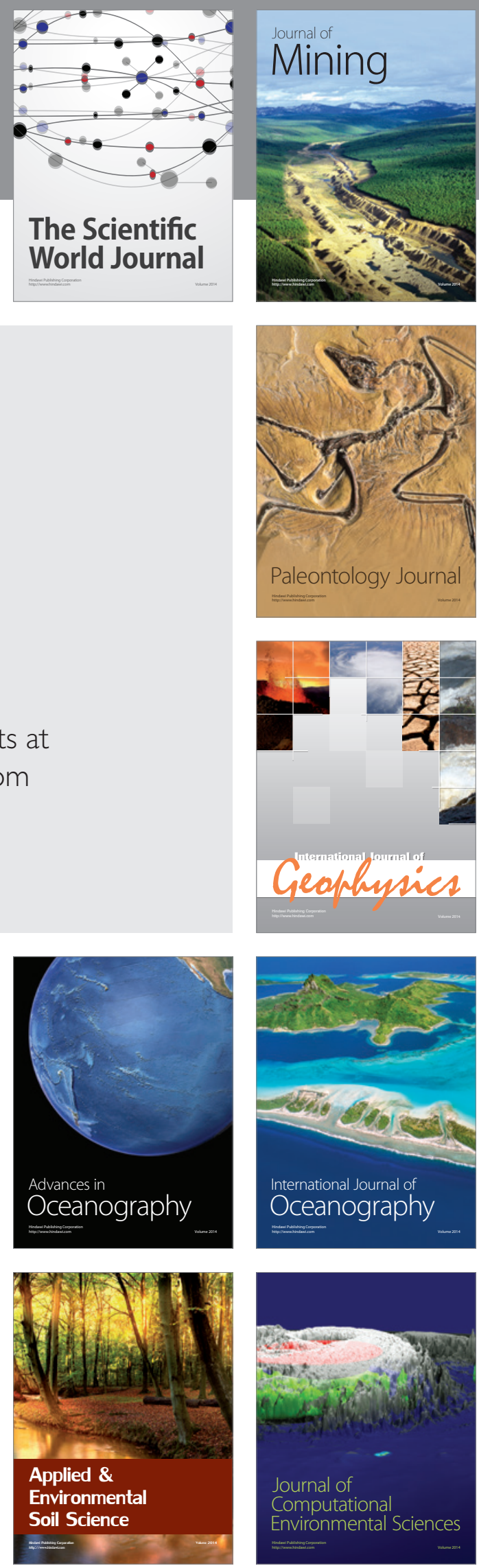